\title{
Understanding the Influence of Pressure and Radial Loads on Stress and Displacement Response of a Rotating Body: The Automobile Wheel
}

\author{
J. Stearns, T. S. Srivatsan, X. Gao, and P. C. Lam \\ Department of Mechanical Engineering, The University of Akron, Akron, OH 44325-3903, USA
}

Received 20 November 2004; Accepted 9 February 2005

This paper highlights the use of the finite element technique for analyzing stress and displacement distributions in wheels of automotive vehicles when subject to the conjoint influence of inflation pressure and radial load. The most commonly used considerations in the design of the rotating body are elucidated. A potentially viable technique for finite element modeling of radial wheel, subjected to loading, is highlighted. The extrinsic influence of inflation pressure on performance of the rotating body, that is, the wheel, is rationalized.

Copyright (C) 2006 J. Stearns et al. This is an open access article distributed under the Creative Commons Attribution License, which permits unrestricted use, distribution, and reproduction in any medium, provided the original work is properly cited.

\section{INTRODUCTION}

Automotive wheels have in the time period spanning the last five decades progressively evolved starting with the early spoke designs of wood and steel, the carryovers from wagon and bicycle technology, flat steel disks, and more recently stamped metal configurations. The metal configurations in the present and newer generation of ground vehicles are made from cast aluminum alloys either in the as-cast or ascast plus forged condition. Historically, successful design was arrived at after years of experience coupled with extensive field testing. Since the 1970s several innovative methods of testing and experimental stress measurements have been developed and tried. During the most recent decade, the procedures have significantly improved by the emergence of a variety of experimental and analytical methods for structural analysis. Durability analyses, that is, fatigue life prediction and reliability methods, for dealing with variations inherent in engineering structures have been used for the study of automotive rims [1-7].

Wheels can be looked upon as safety-related components. Consequently, fatigue performance and state of stress distribution in the rim, under various loading conditions, is a subject of concern. Furthermore, a comprehensive study of performance of the rotating wheel continues to receive significant importance as increased emphasis is laid on decreasing weight by either using lightweight materials or using materials of thin gauge. Although the loads applied on the rotating wheel are complex in nature and the resultant state of stress is usually high, the weight of the rotating body continues to remain as one of the most significant requirement desiring attention. This has necessitated the emergence and use of cast aluminum alloys in both existing and emerging rim designs. Lightweight rims made from a lightweight aluminum alloy are increasingly popular. Further, end-users consider the nature of the rotating wheel on their vehicle as a symbol of status. The sustained drive to reduce fuel consumption provided the impetus for car manufacturers to make rapid strides in altering traditional vehicle designs. Research efforts have found that a smooth outer wheel surface facilitates a reduction in air resistance.

The objective of this paper is to present and discuss the conjoint influence of inflation pressure and radial load on stress and concomitant displacement distribution in the rim of a rotating body, the wheel. The influence of circumferential angle on stress and displacement distribution is also examined. Influence of tire inflation pressure on performance of the rotating body is rationalized. The reference directions and terminologies related to wheel configuration are shown in Figures 1 and 2.

\section{MODELS AND APPLICATION}

\subsection{Analysis under radial load}

The vertical reaction forces exerted by the road surface on four tires balance the total weight of a car on a horizontal. 


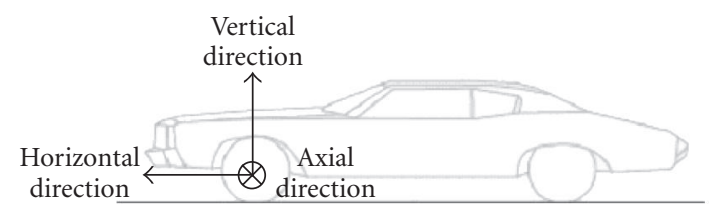

Figure 1: The reference directions.
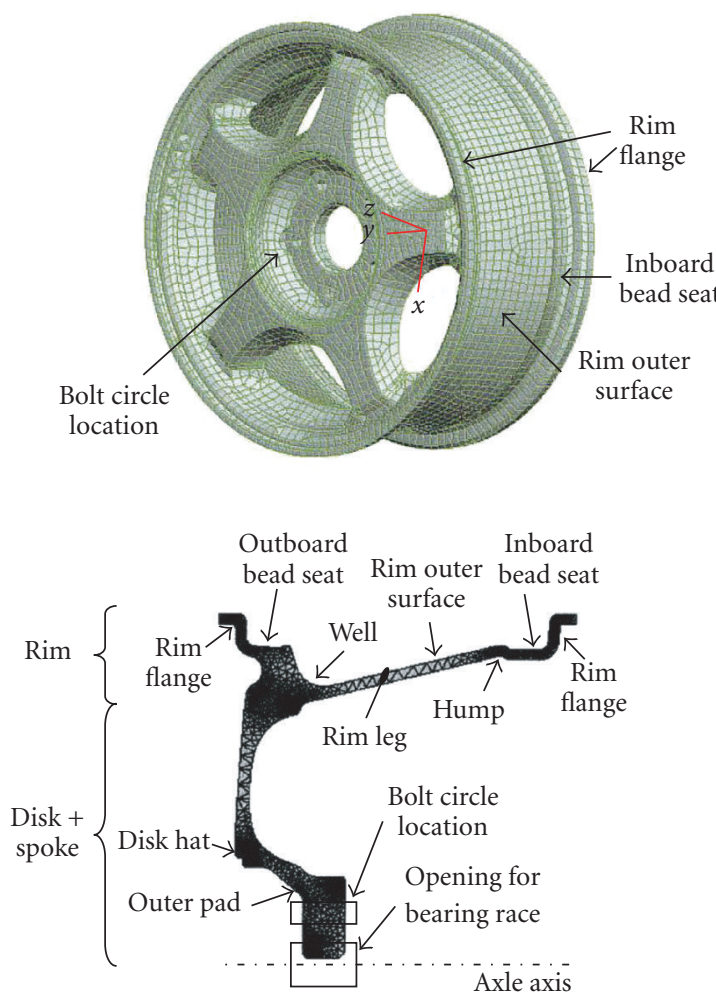

Figure 2: The full finite element model of the wheel and terminology related to a wheel.

Each force passes through the tire and tends to compress the wheel in the radial direction. When the car is in motion, the radial load becomes cyclic in nature with a continuous rotation of the wheel. Hence, a careful evaluation of wheel fatigue strength, under radial load, is important for purposes of structural integrity. According to the society of automotive engineers (SAE), a wheel should maintain structural integrity, without developing macroscopic cracks or undergoing excessive plastic deformation, for more than $4 \times 10^{6}$ rotations, under the influence of a radial load $(Q)$. The radial load is expressed by the equation

$$
Q=S_{r} \cdot F_{r},
$$

where $S_{r}$ is acceleration test factor in conformance with SAE J328 specification $\left(S_{r}=2.2\right)$, and $F_{r}$ is the maximum load on the tire. In this application $F_{r}=7157 \mathrm{~N}$ (1609lbs) and $Q=15.74 \mathrm{KN}$ (3539lbs).

In this research study the radial load is considered to be the force exerted on the bead seats arising as a result of a

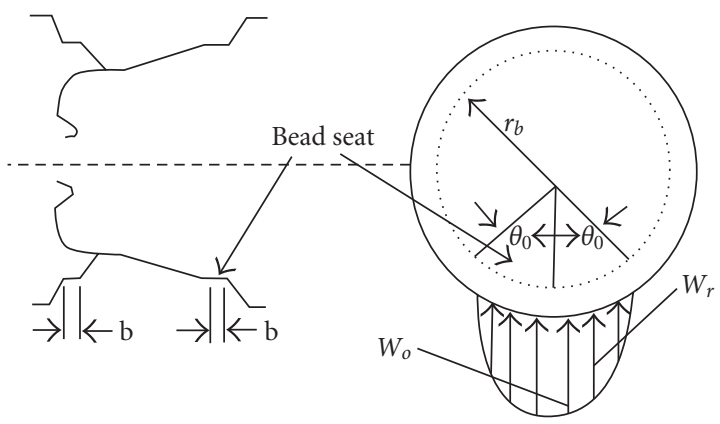

FIGURE 3: A schematic showing the radial loading condition.

vertical reaction of the weight of the automobile on the road surface. The radial load is considered to be equivalent to a static load imparted on both the rim and tire in a direction normal to the surface of the road. Summing horizontal components of the force vector due to the normal loads does not change the resultant state of stress in the rotating wheel. This enables significantly less computation time. For a radial load, the tensile strength of the rim exerts a profound influence on durability, or fatigue life, of the rotating wheel. This ensures a precise evaluation of the stresses to be centered on the rim. In this study, the contact condition between the disk-spoke and the rim well is assumed to be perfectly bonded.

In an actual wheel, the radial load is applied to the wheel at the bead seats with the tire. As a result, distributed pressure is loaded directly onto the bead seat of the model used in this analysis. Pressure, along the circumferential direction, is assumed to follow a cosine function distribution, as shown in Figure 3. Accordingly, the distributed pressure $W_{r}$ is given by the expression

$$
W_{r}=W_{0} \cdot \cos \left(\frac{\pi}{2} \cdot \frac{\theta}{\theta_{0}}\right) .
$$

The total radial load $W$ is calculated using (2) as follows:

$$
F_{r}=2 b \int_{-\theta_{0}}^{\theta_{0}} W_{r} \cdot r_{b} d \theta=8 \cdot b \cdot r_{b} \cdot \theta_{0} \cdot \frac{W_{0}}{\pi},
$$

where $r_{b}$ is the radius, $b$ is the width of the bead seat, and $\theta_{0}$ is the angle of loading. From (3), we can calculate $W_{0}$ with given $F_{r}$. And the distributed pressure, $W_{r}$, on bead seats can be decided by (2). In this analysis, a radial load $\left(F_{r}\right)$ of $17.4 \mathrm{kN}$ ( $4022.5 \mathrm{lbf})$ is applied to the model.

This load magnitude is chosen to be the same as that experienced by an actual wheel in stress measurement experiments. In the stress measurement experiment, the rim was fitted with an aqua-steel tire (model no. P22560R16). The tire was inflated to a pressure of $303 \mathrm{kPa}$ (44 psi). The assembled wheel is then pressed against a flat plate using a load of $17.4 \mathrm{kN}$. Strain gages were fixed at regular intervals on the rim surface, that is, at twenty-degree intervals, on the rim surface, in both the axial and circumferential directions. The central angle $\left(\theta_{0}\right)$ of pressure distribution is $40^{\circ}$ and is determined from the measured strain distribution of the flange of the rim. 


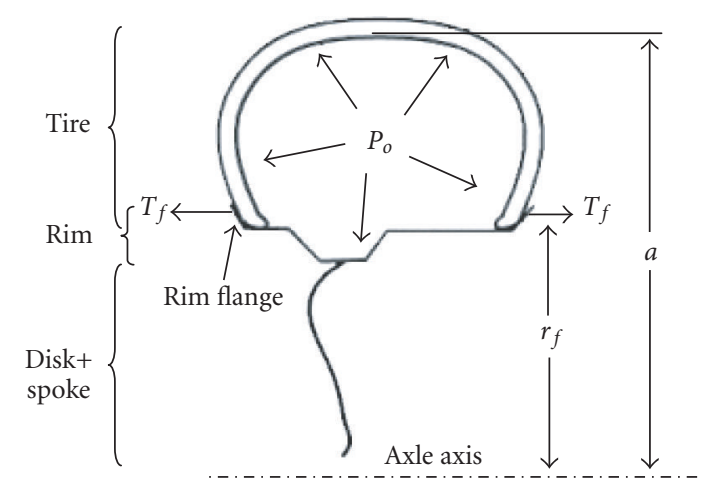

FIgURE 4: A schematic showing the load induced by tire inner pressure.

Pressure is applied to the bead seats on both the inboard side and the outboard side. Half of the pressure on the inboard side is applied to the inboard rim flange, while the other half is applied to the inboard bead seat. This is done because the inboard rim flange tends to deflect easily due to the long inboard rim leg. Consequently, it becomes susceptible to loading from the tire. The loading condition is determined from comparisons made between the measured and calculated stresses on the rim. In a real sense, the ratio of the applied load on the bead seat to the applied load on the rim flange is thought to vary in accordance with the contact condition between the tire and the rim. This is affected by the conjoint and interactive influences of the following: (a) type of tire (bias or radial), (b) air pressure in the tire, (c) reinforcement structure or architecture of the tire, and (d) type of rim used.

\subsection{Influence of tire air pressure}

Air pressure in the tire is assumed to be of constant load having little influence on rotation of the wheel. However, the air pressure in the tire does tend to influence stresses induced on the rim. In subjecting the wheel to use, that is, sustained rotation, the cyclically varying stresses, caused by either the independent or conjoint influences of bending moment and radial load, are superimposed on the constant stress generated by air pressure in the tire. Thus, from a structural point of view, it is essential to evaluate the stress induced on the rim surface by air pressure in the tire.

The air pressure in the tire is exerted on the tire cavity side on the rim surface as shown in Figure 4. The tire air pressure is applied both directly to the rim at its outer surface and indirectly to the rim flange. The air pressure, acting against the sidewall of the tire, generates a load, which is in the axial direction. This load varies in accordance with the following: (a) type of tire, (b) aspect ratio of the cross section of the tire, and (c) reinforcement structure of the tire. To start with, we consider a profile of the cross section of the tire and assembly as exemplified in Figure 4. The axial component of the force $F_{p}$, which results from the inflation pressure $\left(P_{0}\right)$ in the tire, is estimated from the relationship

$$
F_{p}=\pi\left(a^{2}-r_{f}^{2}\right) P_{0},
$$

where $a$ is the design radius of the tire and $r_{f}$ is the radius of the loading point on the rim flange. Since axial load is supported by both the tread of the tire and the flange of the rim, approximately one half of the load is assumed to be borne by each part. The load on a unit length of the circumference of the rim flange of the rotating wheel is calculated using the expression

$$
T_{f}=\frac{F_{p}}{4 \pi \cdot r_{f}}=\left(a^{2}-r_{f}^{2}\right) \frac{P_{0}}{4 \cdot r_{f}} .
$$

The applied air pressure in the tire chosen was (a) 0, (b) 117, and (c) $241 \mathrm{kPa}$.

\subsection{Finite element modeling}

A full three-dimensional stress analysis was performed using the mesh subdivision shown in Figure 2. The finite element model was constructed such that the model geometry exactly duplicates the rim. The finite element model consists of (a) 32059 brick and wedge elements, (b) 18021 nodes, and (c) 432504 degrees of freedom. Cast aluminum alloy (A356T6) was the material chosen for the rim, with properties of Young's modulus $=73.1 \mathrm{GPa}$, Poisson's ratio of 0.33 and a yield strength of $275,760 \mathrm{kPa}$. The boundary conditions at the bolt circle were fixed. The forces from (2) and (5) were applied to the positions outlined in the preceding subsections. The tire air pressure is applied on the rim outer surface between the inboard bead seat and outboard bead seat. The ALGOR finite element system was used to analyze the problem.

The nomenclatures of key locations on the wheel are shown in Figure 2. The key locations are (a) the outboard and inboard bead seats, (b) well and hump on the rim, and (c) the disk hat and outer pad. These were investigated on the disk portion of the wheel.

\section{RESULTS AND DISCUSSION}

\subsection{Von Mises stress distribution}

The distribution of Von Mises stress for an air pressure of $241 \mathrm{kPa}$ is shown in Figure 5. It is observed that the stresses are well distributed along the disk portion of the rim. This is clearly indicative of safe design practice. The Von Mises stress calculated in the disk is much lower than the Von Mises stress calculated in the rim. Of all the critical areas in the rotating wheel, the in-board bead seat is identified as being the highest stressed area in the wheel. Since the Von Mises stresses are low, the stress distribution fails to provide adequate information pertaining to the design criterion for bead retention.

\subsection{Displacement distribution}

Displacement becomes a key design factor and is shown in Figure 6. The magnitude of the displacement vector is greatest on the inboard side of the rim, which is free to flex when 


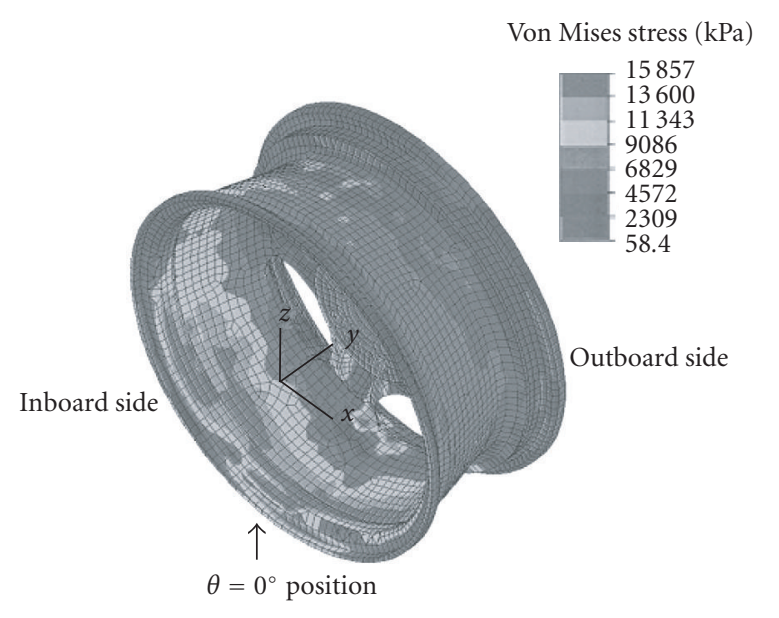

Figure 5: The Von Mises stress distribution in the wheel under $241 \mathrm{kPa}$ pressure.

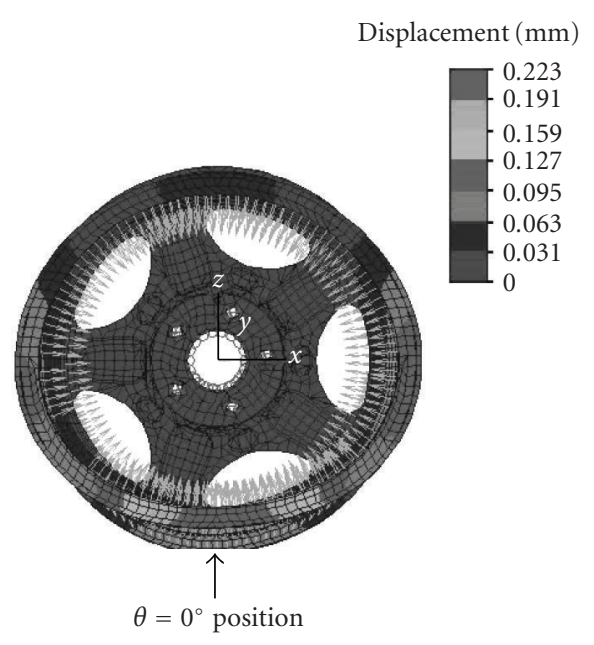

Figure 6: The displacement magnitude of the rim at an inflation pressure of $0 \mathrm{kPa}$ (view from inboard side).

compared to the outboard side that is supported by the disk. The finite element model predicts a maximum displacement of $0.223 \mathrm{~mm}$. The deformed shape of the wheel is not symmetric with respect to the vertical plane since the spokes are not arranged symmetrically with respect to the plane in this finite element model. Nevertheless, displacement is symmetrical, implying that the rotating wheel tends to distort into an oval shape about the point of loading. This is encouraging when rationalizing the reason as to why the quarter model fails to accurately predict full-symmetry displacements. The half symmetry model yields consistent results, depicting a similar shape for the displacement and its magnitude. However, the quarter symmetry model fails to predict the same trend in deformation. Other investigators [6-10] have successfully used the full and one-half symmetry models in their analysis.
Upon application of a radial load the rim bends inward at $\theta=0^{\circ}$. This occurs because of an offset, along the axial direction, between the disk pad and the center of the rim width. The end view of the displaced rim is shown in Figure 7. The inboard flange of the rim deforms elliptically when compared to the outboard rim flange, which is supported by the disk. Symmetric bending of the rim occurs as a direct result of varying deformation between the inboard side of the rim and the outboard side of the rim. When the wheel is put in motion, that is, rotation, the inboard flange bends inward when $\theta=0^{\circ}$ and bends outward when $\theta=90^{\circ}$. However, when $\theta=180^{\circ}$ the inboard flange bends inward and bends outward when $\theta=270^{\circ}$ just as for $\theta=90^{\circ}$.

Results at both the disk hat and the outer pad reveal the displacements to be essentially low when compared to other key locations on the surface of the rim. Variations in inflation pressure resulted in small differences in the maximum displacement of the order of $0.002 \mathrm{~mm}$, which is negligible. For all of the inflation pressures examined in this study,

(a) the highest displacements occurred when the rotating body was loaded at a circumferential angle of $0^{\circ}$,

(b) the minimum values occurred when the circumferential angle was $70^{\circ}$ and $170^{\circ}$ (Figure 8).

For $\theta<70^{\circ}$ the displacement is larger at the higher inflation pressures, and when $\theta>70^{\circ}$ the displacements become larger at the higher inflation pressures. A similar effect was seen at the outer pad even though the displacements are negligible.

\subsection{Maximum stress distribution}

The maximum principal stress on the disk hat has a global maximum occurring at the point of loading $\left(0^{\circ}\right)$ and steadily decreasing as the circumferential angle $(\theta)$ increases (Figure 9). In this case, the high inflation pressure in the rotating tire yields higher principal stresses for all angles around the wheel. As the circumferential angle approaches $140^{\circ}$ and becomes larger, the change in value of stress becomes negligible for angles greater than $140^{\circ}$ and reveals a decline near the top of the wheel at $180^{\circ}$.

The influence of inflation pressure on maximum principal stress on the disk hat area is shown in Figure 10. This figure reveals a monotonic decrease in the level of stress for angles less than $70^{\circ}$, with an inflation pressure of $241 \mathrm{kPa}$ yielding the highest stresses. However, for angles greater than $70^{\circ}$ the role of inflation pressure decreases the magnitude of stress (the stresses at $0 \mathrm{kPa}$ are greater). The largest maximum principal stress occurs at $0^{\circ}$.

The maximum principal stress at the outer pad of the rim varies in accordance with the disk hat. Lower values of air pressure in the tire results in higher stress values at this location for angles greater than $40^{\circ}$. For angles less than $40^{\circ}$, the higher values of tire air pressure result in higher values of stress at this location.

Influence of inflation pressure on stress at the outer pad is shown in Figure 11 with an observable variation in stress occurring in the range of circumferential angles of $60^{\circ}$ and $90^{\circ}$. 


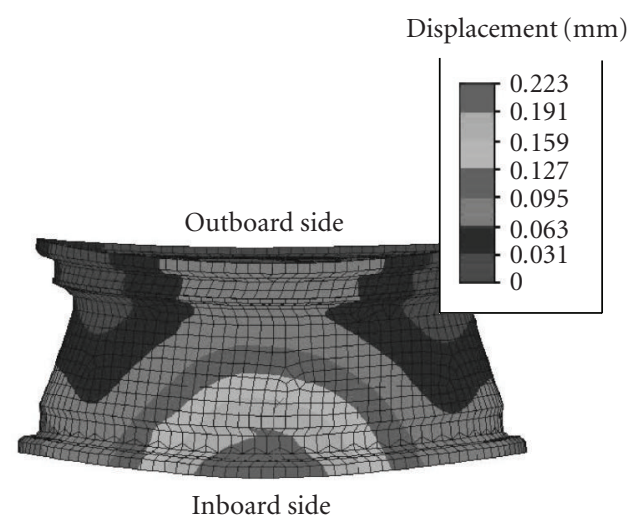

Figure 7: The end view of the deformed rim (view from $\theta=0^{\circ}$ direction).

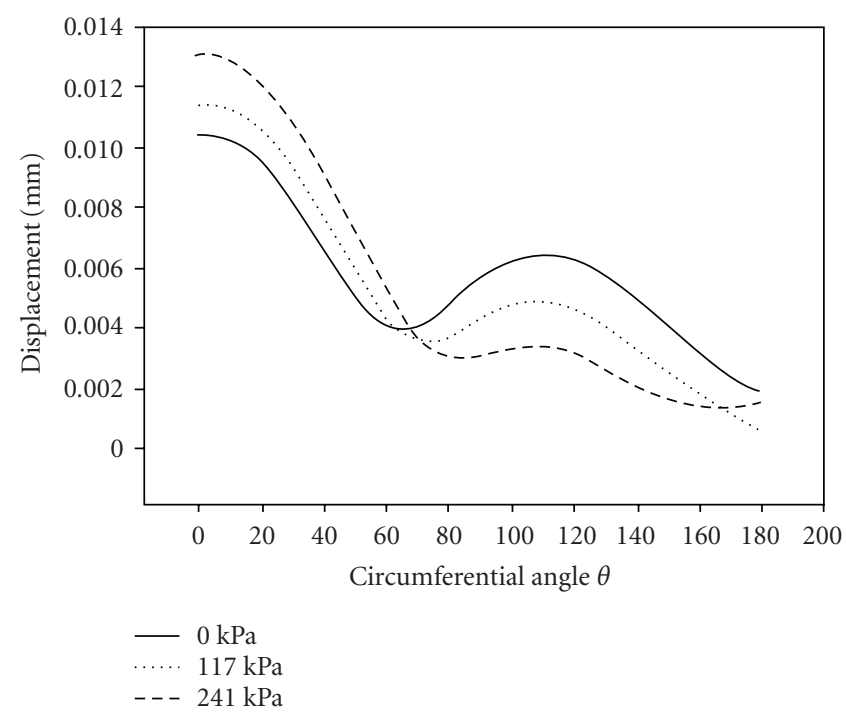

Figure 8: The magnitude of the displacement vector on the disk hat near the bolt circle as a function of circumferential angle for inflation pressure of $0 \mathrm{kPa}, 117 \mathrm{kPa}$, and $241 \mathrm{kPa}$.

At a circumferential angle of $0^{\circ}$ the stresses are tensile in nature, with the maximum occurring at $60^{\circ}$ and rapidly decreasing to a minimum at $100^{\circ}$. In summary, influence of inflation pressure on the maximum principal stress is small. The stresses and resultant deflections on the disk hat are low when compared to other key locations on the surface of the rim. Also, minute variations in stresses and displacements are low as inflation pressure changes. In a few cases, an inflation pressure of zero in the rotating tire resulted in the highest stress magnitudes and resulting deflections. This was found to be dependent on the circumferential angle.

In Figure 12 is shown a progressive decrease in principal stress in the spoke area, with progression around the rim, for circumferential angles from $0^{\circ}$ to $360^{\circ}$. It is worthy to note that air pressure has little influence at this location of the wheel. However, influence of air pressure at locations of the spoke at $120^{\circ}$ and $225^{\circ}$ can be seen, as the difference in magnitude of stresses becomes negligible. This clearly indicates the effective reinforcement of the spoke. The geometry of the spoke is the thickest portion on the entire assembly of the rotating wheel, with five spokes spanning the wheel circumference.

The inboard bead seat and rim hump, geometrically close to each other on the rim surface, were the other critical areas that were investigated. In Figure 13 the maximum principal stress is approximately symmetric about $\theta=60^{\circ}$ for $20^{\circ}<$ $\theta<120^{\circ}$ with the highest magnitude occurring at $60^{\circ}$. For $\theta>120^{\circ}$ the maximum principal stress remains a constant value.

The influence of inflation pressure on displacement is shown in Figure 14. It is observed that the curves exhibit similar trends with only a marginal change in magnitude. At an inflation pressure of zero, the displacements are greatest. However, at $117 \mathrm{kPa}$ and $241 \mathrm{kPa}$ the displacements are less at all of the key locations. A higher displacement occurs at the $0^{\circ}$ circumferential angle and the value of displacement progressively decreases to $180^{\circ}$, with a local maximum occurring at the circumferential angle of $90^{\circ}$, which was taken as the reference. The displacement experienced by the hump was found to be less than the displacement at the bead seat. This is ascribed to its close proximity to both the bead seat and the outer pad. Consequently, local moments generated at this location are smaller in comparison to the bead seat.

The maximum principal stresses on the bead seat and the hump are exemplified in Figure 15. The stresses in the bead seat are constant around the rim. However, the rim hump experiences a noticeable variation in stress. For the rim hump the displacement is a local maximum at $0^{\circ}$ resulting in a maximum value of stress at this location. The hump reveals for circumferential angles of $0^{\circ}$ and $90^{\circ}$ that the displacements are positive. The local principal stresses are primarily compressive in nature at $0^{\circ}$ and tensile in nature at $90^{\circ}$. This was found to be true at all the three inflation pressures investigated in the rotating tire.

Examining the stress distribution over the bead seat, as a function of inflation pressure of the tire (Figure 13), a wide variation is observed in the magnitude of principal stress both at and beyond a circumferential angle of $90^{\circ}$. A shift, or redistribution of stresses, occurs when the inflation pressure in the tire drops from $117 \mathrm{kPa}$ to $0 \mathrm{kPa}$. Overall, an estimated $20^{\circ}$ shift occurs. However, no apparent shift in stresses was evident when the inflation pressure decreased from $241 \mathrm{kPa}$ to $117 \mathrm{kPa}$. For an inflation pressure of $241 \mathrm{kPa}$ the stresses vary greatly with circumferential angle, in the range from $130^{\circ}$ to $170^{\circ}$. Thus, the area of the bead seat is identified as having the largest magnitude of stresses induced and resultant deflection. This is identified to be the critical design location for the rim of the rotating wheel.

Based on results obtained, the stresses on the rim are low and the magnitude is well below the endurance limit of aluminum alloy A356-T6. However, at these locations damage due to fatigue is favored to occur due to local stress concentration. Locations on the rim surface that are of concern are (a) the bead seat, (b) the well, and (c) the rim hump. At the microscopic level, the stress risers present in these 


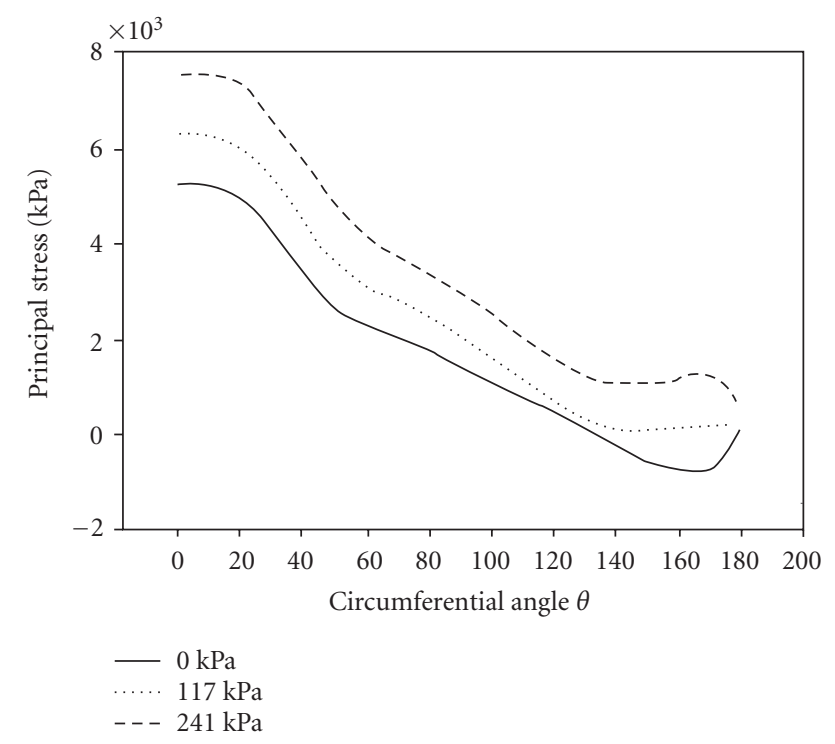

FIgURE 9: The maximum principal stress on the hat near the bolt circle as a function of circumferential angle for inflation pressure of $0 \mathrm{kPa}, 117 \mathrm{kPa}$, and $241 \mathrm{kPa}$.

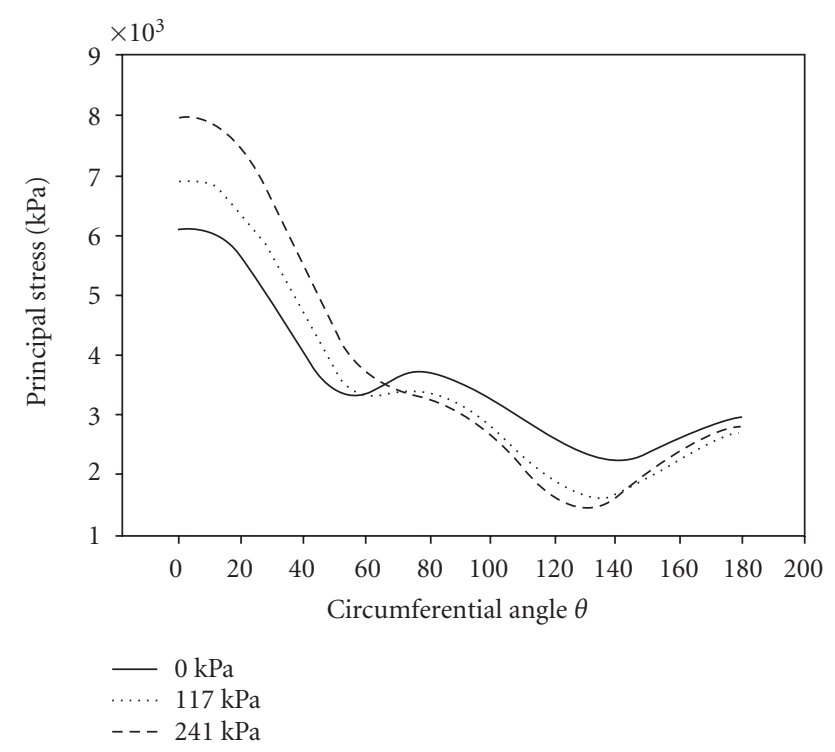

FIGURE 10: Influence of inflation pressure on the maximum principal stress at the disk hat.

locations would tend to promote the occurrence of local plasticity in the deformation zone surrounding these areas. Repeated loading causes plastic deformation to occur very early in the use of the rim with the concomitant initiation and rapid propagation of microscopic cracks.

The highest deflections observed in the aluminium alloy rim, chosen in this study (A356-T6), are relatively small in the bead seat area. This is clearly indicative that the tire will tend not to dislodge itself from the rim. However, during the impact loading, which wheel designers conservatively select and use is a loading factor of three times the static load.

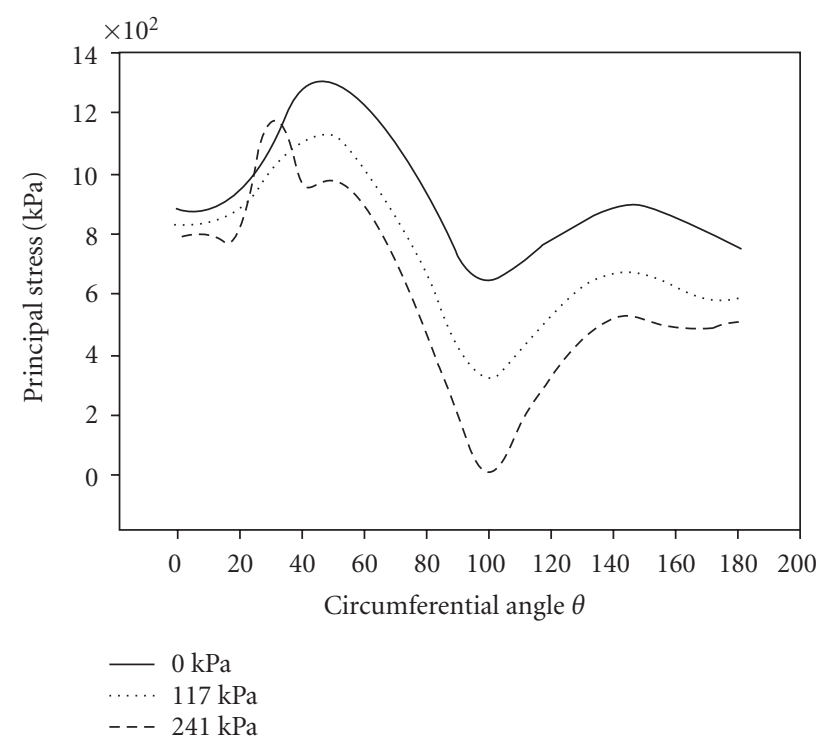

FIGURE 11: Influence of inflation pressure on the maximum principal stress at the outer pad.

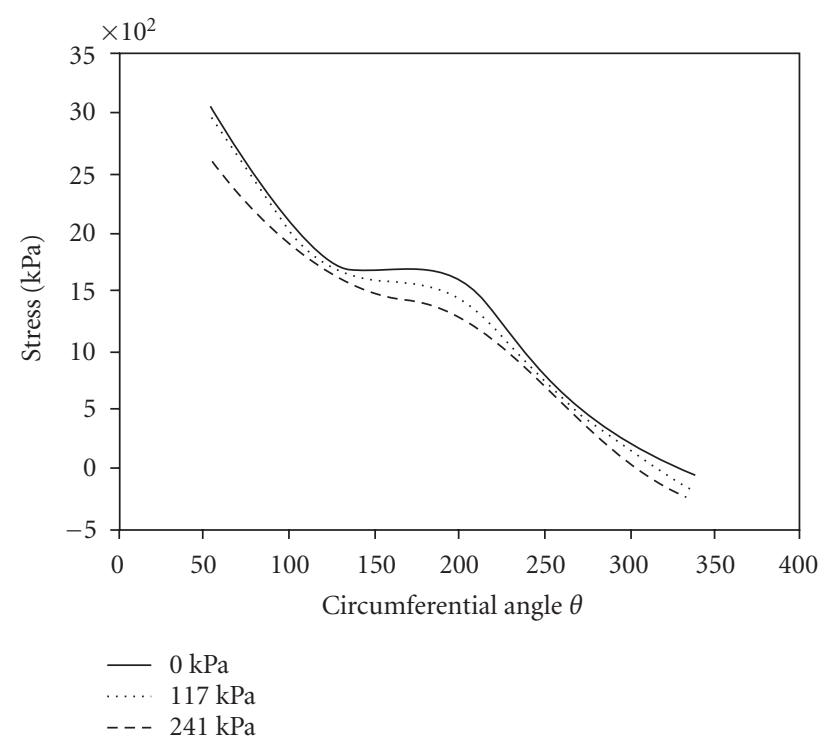

FIGURE 12: Influence of inflation pressure on the development of the maximum principal stress in the area of the spoke.

This observation was also noticed by researchers associated with the SAE. The static model was rerun using a value three times the current load so as to observe if significant deflections were an exacerbating phenomenon. The highest deflection was found to occur at the $90^{\circ}$ location, with a maximum value of $0.668 \mathrm{~mm}$. The resultant highest maximum principal stress was $4.58 \mathrm{MPa}$. This is expected due to a linear stress analysis performed here. With a predicted endurance limit of $1 / 2$ of the ultimate strength of aluminum (31 GPa) being $15.5 \mathrm{GPa}$, stresses are low enough to ensure longevity of the wheel. 


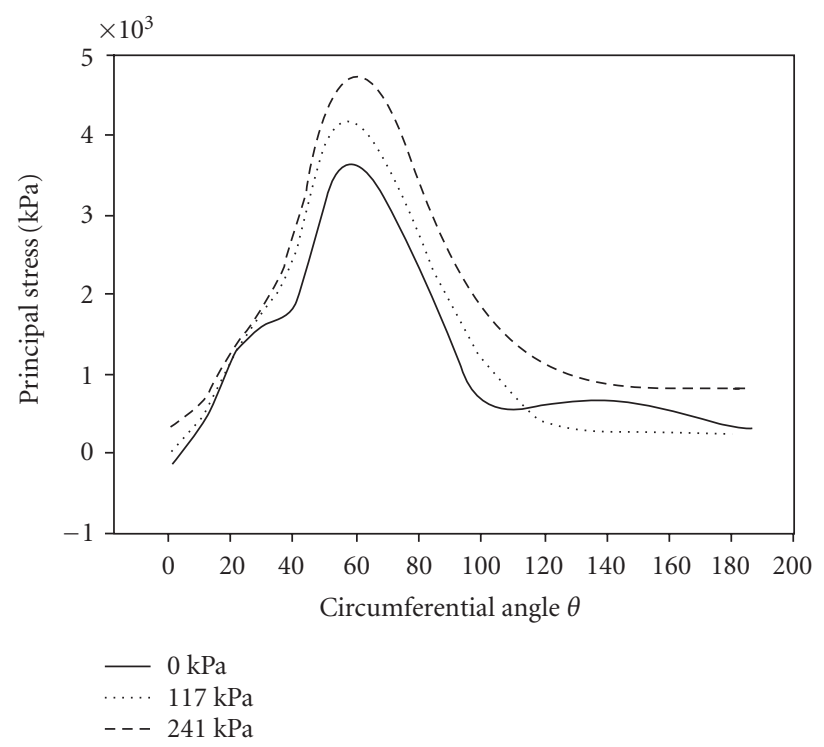

FIGURE 13: Influence of inflation pressure on the maximum principal stress distribution at the inboard bead seat.

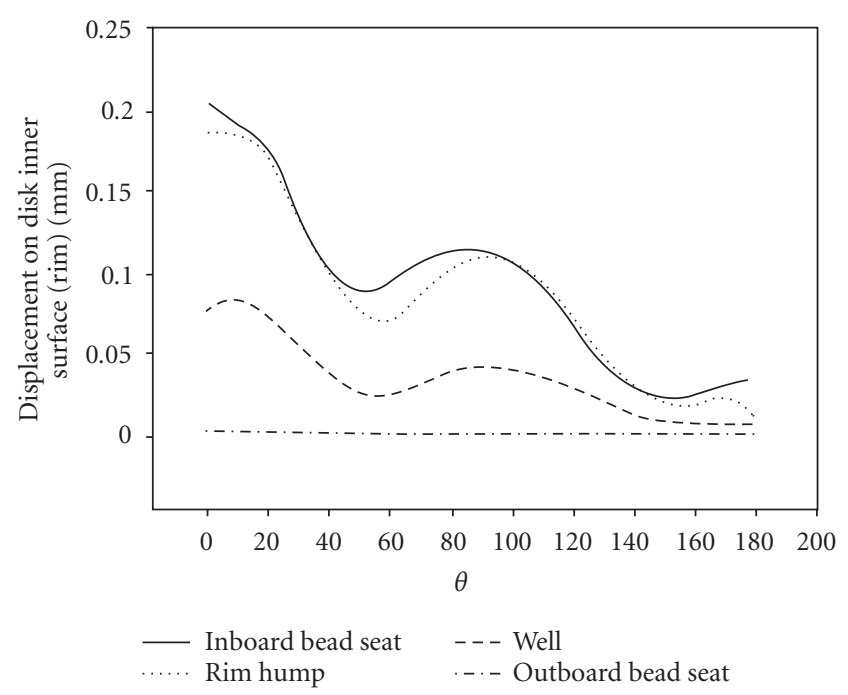

FIGURE 14: Variation of displacement of the aluminum alloy rim, with circumferential angle, for an inflation pressure of $0 \mathrm{kPa}$.

A location on the rim surface that is of concern is the "well" primarily because maximum stress occurs as a result of "local" bending stresses. A detailed examination of rim geometry reveals that the inside surface essentially remains unsupported by the disk. In this case it is free to flex about the well. However, if the applied forces are high then it can cause the tire to dislodge itself from the bead seat on the inside or alternatively the impact loading can cause the occurrence of permanent damage to the rim. In summary, the wheel can be considered a safety device. Damage occurring as a result of an optimized geometry and resultant fluctuations in stress is not an option for the designer. Since most wheels are designed to

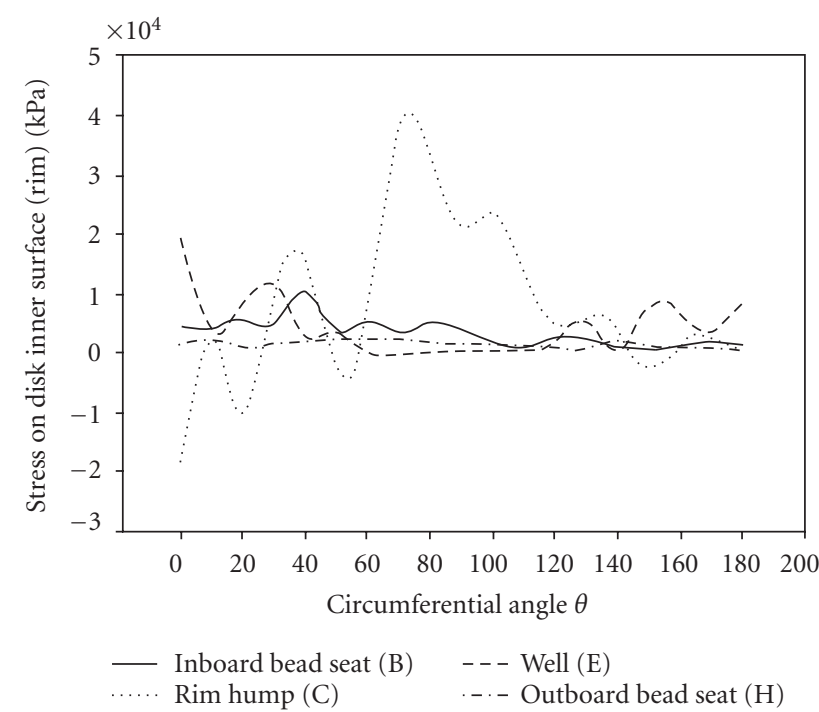

FIGURE 15: Variation of the maximum principal stress on the rim as a function of circumferential angle for an inflation pressure of $0 \mathrm{kPa}$.

last a lifetime, the predicted finite element analysis validates this point.

\section{CONCLUSIONS}

Based on the analysis performed on the influence of pressure and radial load on stress and resultant displacement response of a rotating wheel, the following are the observations made.

(1) Inflation pressure does have a direct effect on the state of stress in an automobile rim under the influence of a load of the maximum tire rating.

(2) Under a radial load the rim tends to ovalize about the point of contact, with a maximum displacement occurring at location of the bead seat.

(3) The inside bead seat deflects the highest and is prone to loss of air pressure as a result of dislodgement of the tire on the rim.

(4) The stresses are much higher in the rim than in the disk.

(5) The critical design areas of the wheel are the inboard bead seat and the well.

\section{ACKNOWLEDGMENT}

The authors extend sincere thanks and appreciation to the Goodyear Tire and Rubber Company (Akron, Ohio, USA) for partial support of this research work.

\section{REFERENCES}

[1] P. Reipert, "Optimization of an extremely light cast aluminum alloy wheel rim," International Journal of Vehicle Design, vol. 6, no. 4-5, pp. 509-513, 1985.

[2] A. Currie and B. Wilson, Finite Element Analysis of an Automotive Wheel-A Case History, National Conference Publication, Institution of Engineers, Australia, pp. 16-20, April 1981. 
[3] Institution of Mechanical Engineers, Ed., Automobile Wheels and Tyres, I. Mech. E Conference Publications, Conference Code 03757, London, UK, December 1983.

[4] M. Reisner and R. DeVries, "Finite Element Analysis and Structural Optimization of Vehicle Wheels," SAE Technical Paper Series, pp20.

[5] The Tire and Rim Association, 1998 Yearbook.

[6] N. Mizoguchii and A. Nishimura, "Stress analysis and fatigue strength of sheet fabricated aluminum wheels," $R \& D$ Magazine, vol. 32, no. 2, pp. 8-12, 1982.

[7] M. Kawashima, "Stress evaluation of automotive steel road wheel under radial load," Transactions of the Japan Society of Mechanical Engineers, Part C, vol. 55, no. 513, pp. 1254-1258, 1989.

[8] K. Morita and M. Kawashima, "Finite element stress analysis of a car wheel," Sumitomo Metals, vol. 39, no. 3, pp. 245-263, 1987.

[9] K. Morita and K. Ishihara, "Finite element analysis of a steel car wheel," Sumitomo Search, no. 35, pp. 89-106, 1987.

[10] J. A. Sherwood, B. K. Fussell, W. R. Edwards, T. S. Gross, and D. W. Watt, "Study of the pressure distribution on an aircraft tire-wheel interface," Journal of Aircraft, vol. 32, no. 5, pp. 921928, 1995. 

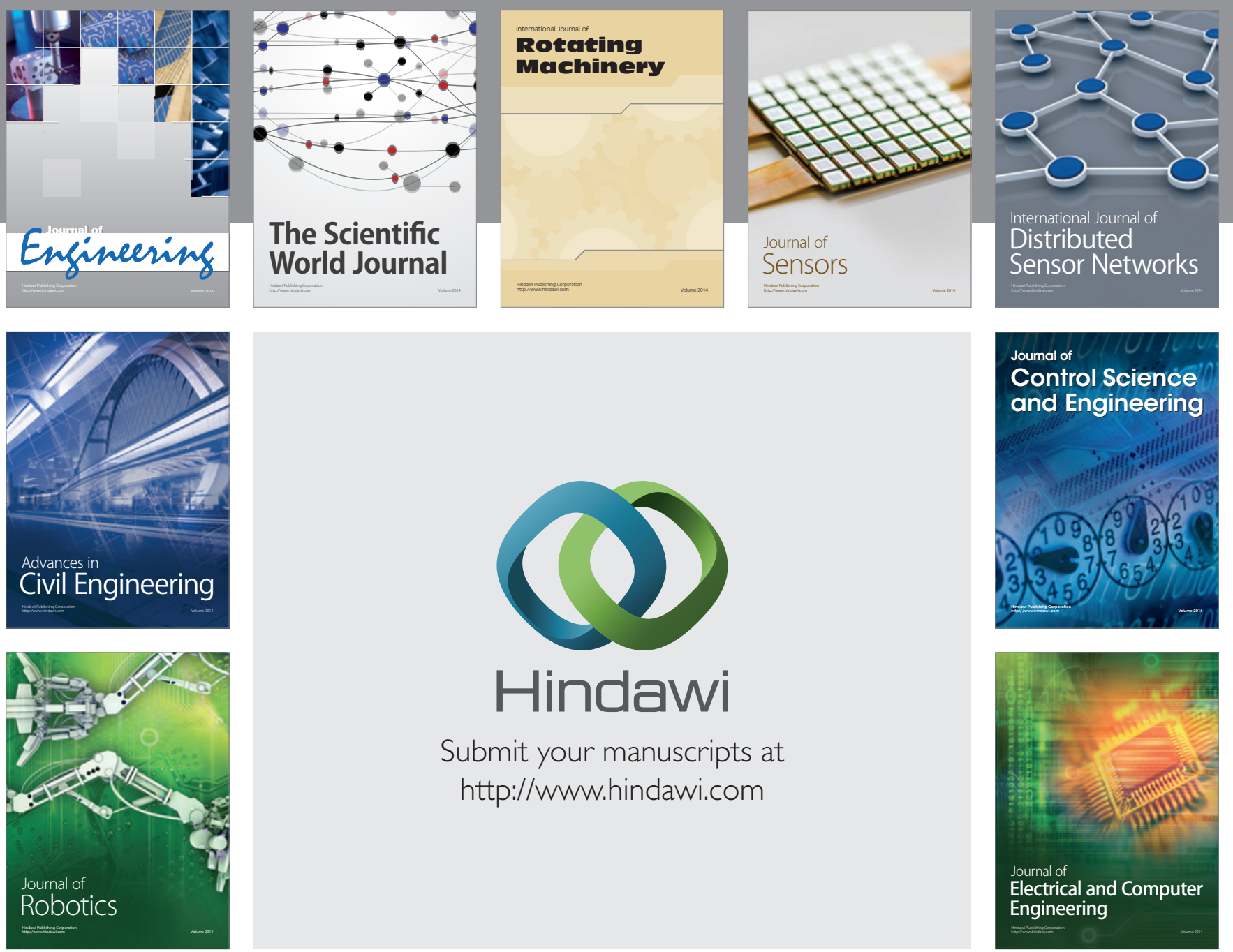

Submit your manuscripts at

http://www.hindawi.com
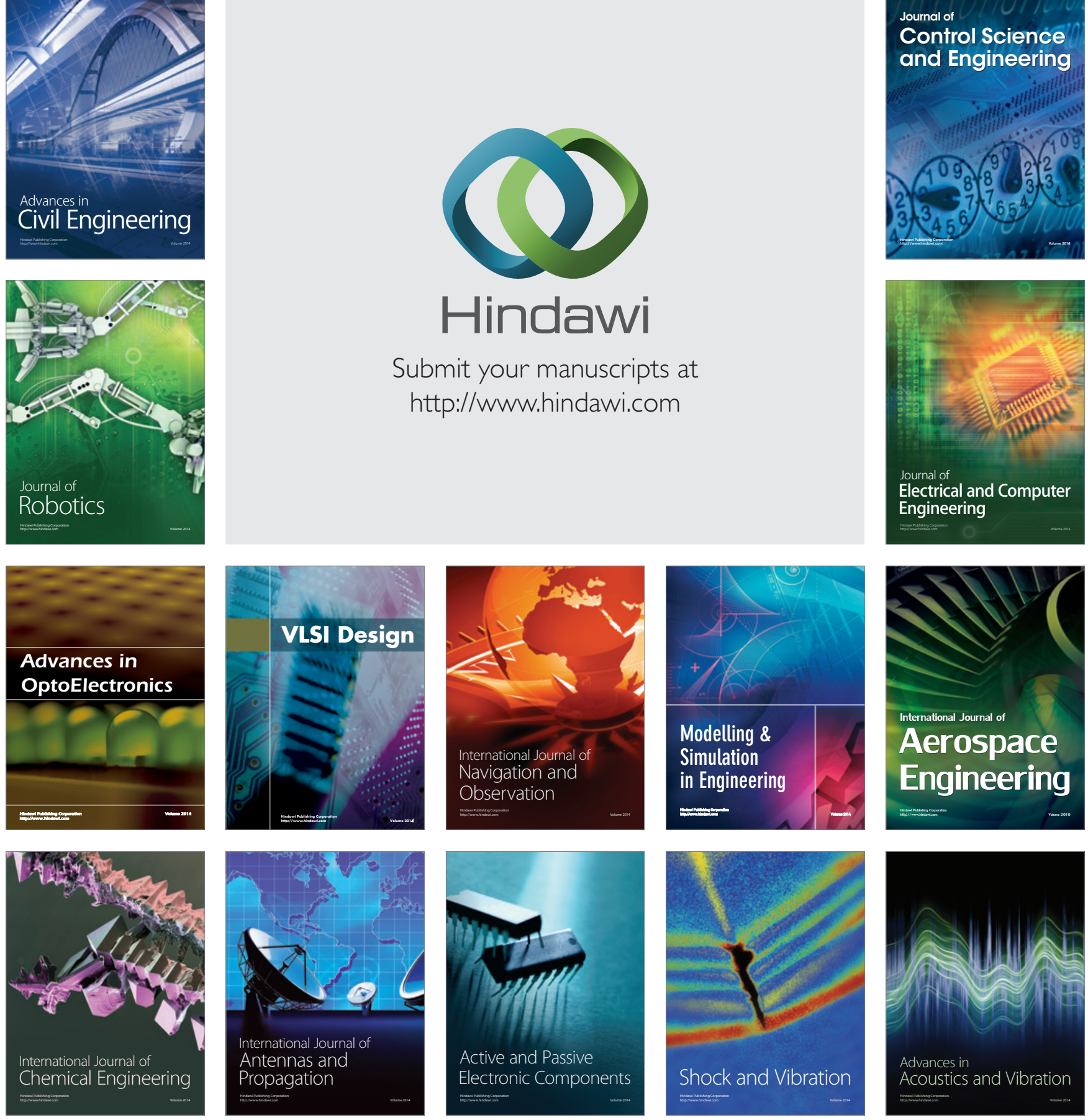